\title{
Desafios e aprendizados com o ensino remoto por professores da educação básica
}

\author{
Lucicleide Araújo de Sousa Alves $^{1,2}$ (D); Alexandra da Costa Souza Martins ${ }^{3}$ (D) ; Adriana Alves de \\ Moura $^{2}$ \\ ${ }^{1}$ Universidade Católica de Brasília (UCB), ${ }^{2}$ Secretaria de Estado de Educação do Distrito Federal, ${ }^{3}$ Centro \\ Universitário UniProjeção, Brasil
}

Resumo. Objetivou-se conhecer a percepção de professores da educação básica, das cinco regiões brasileiras, quanto aos desafios e aprendizados em aulas remotas. É uma pesquisa exploratória de abordagem qualitativa. Utilizou-se o questionário on-line: dados sociodemográficos e relacionados à prática educacional; conhecimento e utilização de tecnologias; desafios e aprendizados com o ensino remoto. $\mathrm{O}$ estudo revelou a necessidade de repensar a utilização das tecnologias digitais na educação após a pandemia, de investir na formação e o de analisar as condições escolares quanto aos recursos e possibilidades de utilização. Concluiu-se que o maior desafio foi a utilização das tecnologias com despreparo e a importância do papel do professor como mediador da aprendizagem, foi um dos maiores aprendizados.

Palavras-chave: tecnologias digitais; percepção; desafios; aprendizados.

Desafíos y aprendizajes con la enseñanza remota de los docentes de educación básica Resumen. El objetivo es conocer la percepción de los profesores de educación básica de las cinco regiones brasileñas sobre los desafíos y los aprendizajes en clases remotas. Se trata de una investigación exploratoria de enfoque cualitativo. Se utilizó un cuestionario online: datos sociodemográficos y relacionados con la práctica educativa; conocimiento y uso de las tecnologías; retos y aprendizaje con la enseñanza remota. El estudio evidenció la necesidad de replantear el uso de las tecnologías digitales en la educación tras la pandemia, de invertir en formación y analizar las condiciones escolares en cuanto a recursos y posibilidades de utilización. Se concluyó que el mayor reto fue utilizar las tecnologías sin preparación, así como la importancia del papel del profesor como mediador del aprendizaje fue uno de los mayores aprendizajes.

Palabras clave: tecnologías digitales; percepción; desafíos; aprendizajes.

\section{Challenges and learning from remote teaching by basic education teachers}

Abstract, The objective was to know the perception of basic education teachers, from the five Brazilian regions, regarding the challenges and learning in remote classes. It is an exploratory research with a qualitative approach. The online questionnaire was used: sociodemographic data and related to educational practice; knowledge and use of technologies; challenges and learning from remote education. The study revealed the need to rethink the use of digital technologies in education after the pandemic, to invest in training and to analyze school conditions regarding resources and possibilities of use. It was concluded that the biggest challenge was the use of technologies with unpreparedness and the importance of the teacher's role as a learning mediator, was one of the greatest learnings.

Keywords: Pandemic; Digital technologies; Challenges; Learnings.

\section{Introdução}

A crise de ordem sanitarista, no final da segunda década do século XXI afetou toda a humanidade. O planeta quase entrou em colapso no que se refere à saúde e a humanidade teve de desacelerar todas as suas atividades em prol da existência da vida e sua continuidade. Todo esse caos foi gerado pela pandemia COVID-19, iniciada na China em dezembro de 2019, cujas esferas da vida social, em todas as suas instâncias e áreas profissionais, tiveram de se reinventar para se manterem no mercado e não serem vítimas da estatística do desemprego. Esta situação anômala e inesperada colocou a sociedade mundial em uma luta pela sobrevivência em virtude de tantas incertezas. 
Vários decretos foram instituídos e cumpridos em coletividade. As tecnologias digitais foram os meios mais utilizados para a manutenção da comunicação e relação virtual com os familiares, com os amigos e de vinculação com o trabalho.

Na educação, para dar continuidade às atividades educativas, muitas foram as tecnologias que professores, estudantes e pais tiveram de se apropriar - em tempos formativos records - para uma reconexão com o processo de conhecimento. A aula na modalidade de ensino presencial/remota foi a "opção" desafiadora para a superação do distanciamento social e para dar continuidade ao ano letivo.

Como assegura Morin (2007) na crise urgem os problemas, mas também dela as prováveis soluções. "Um bastão sempre tem duas extremidades" (Nicolescu, 1999, p. 33). O que antes se apresentava tão distante de acontecer, a utilização do computador como um recurso capaz de transportar a lugares virtuais, de conectar a pessoas longínquas e de resgatar inúmeras informações, segundo já apontava Murray (2003), na década de 1990, bem como uma "formação para e com as tecnologias" proposta por Belloni (2005) e, há tempos almejada, fez-se mais que urgente e necessária, provocando uma revolução nos processos formativos de ensino e de aprendizagem e nas formas de ministrar as aulas, principalmente na modalidade presencial, foco deste estudo.

Nesse contexto, o lugar de encontro presencialmente constituído - a escola passou a se situar e acontecer em um dos pontos da rede. A sala de aula: os espaços da casa. Os computadores e celulares: a saída, o lugar para o encontro, a troca de informações e saberes, o espaço para a comunicação e relação entre os professores e os estudantes no âmbito educacional.

Diante de todo este contexto, o foco deste artigo é no ensino remoto, com o objetivo de conhecer a percepção de docentes da educação básica que vivenciaram a experiência de ministrarem aulas por meio da utilização de tecnologias em rede, em tempos pandêmicos, bem como os desafios e aprendizados envolvidos. ]

Para tanto, apresenta-se inicialmente o histórico da pandemia COVID-19 e suas implicações no cenário educacional brasileiro. Depois, discorrer-se-á sobre as diferenças entre Educação a Distância eAulas Remotas. Em seguida, serão abordadas as percepções dos professores quanto aos desafios e possibilidades, bem como os aprendizados extraídos de tempos pandêmicos e confinamento social.

\section{Histórico da COVID-19 e suas Implicações no Cenário Educacional Brasileiro}

A Organização Mundial da Saúde (OMS) passou a considerar o surto da COVID-19 como pandemia em março de 2020, fato que colocou a sociedade mundial em alerta e provocou posteriormente o fechamento de escolas e comércio em diversas nações, ficando abertos apenas os de necessidades essenciais. No Brasil, por meio do Decreto Legislativo N. ${ }^{\circ} 6$ de 20/03/2020, o país reconhece a ocorrência do estado de calamidade pública.

Dada a emergência da situação e as incertezas do futuro, vários documentos foram editados por Conselhos Estaduais e Municipais de Educação (CNE): 
Os Conselhos Estaduais de Educação de diversos estados e vários Conselhos Municipais de Educação emitiram resoluções e/ou pareceres orientativos para as instituições de ensino pertencentes aos seus respectivos sistemas sobre a reorganização do calendário escolar e uso de atividades não presenciais. (Parecer CNE/CP nº 9/2020)

No cenário educacional brasileiro, as instituições de ensino passaram a replanejar o calendário escolar, mesmo com as incertezas do futuro. Os professores adotaram novas metodologias de ensino, planejando aulas especialmente com a utilização de recursos tecnológicos digitais.

A sala de aula tornou-se virtual, sendo adentrada não mais no espaço físico da escola, tradicionalmente constituída - envólucra por seus muros - mas nos Ambientes Virtuais de Aprendizagem (AVA), em que professores e estudantes passaram a dialogar e a se relacionar.

As famílias, muitas anteriormente sem tempo de acompanhar a vida escolar dos seus filhos, em função das demandas do mundo capitalista e acelerado, se viram obrigadas pela necessidade não somente de acompanhá-los como também de ajudá-los diretamente no processo de ensino, especialmente para o grupo de alunos mais jovens (educação infantil e anos iniciais do ensino fundamental), que também passaram a ter aulas remotas por meio de tecnologias digitais, entre elas, o uso de plataformas digitais.

No que diz respeito à legalização quanto ao regime de aulas não presenciais, desenvolvidas remotamente, vários foram os documentos publicados pelo Ministério da Educação, pelos Conselhos Estaduais de Educação (CNE) e demais órgãos municipais competentes, explicando e orientando a escola e a família sobre como conduzir o processo de ensinagem distante da sala de aula presencial.

Nunca esteve tão evidente o papel preponderante e determinante da família para a promoção da aprendizagem. Lembrou-se nessas bases normativas que o papel da família é essencial em todas as etapas da "Educação Básica, para além do contexto imposto pela pandemia e isolamento social" (Brasil, 2020, p.1).

A pandemia foi um problema para além da suspensão das aulas presenciais, afetando não apenas o calendário escolar, mas despertando também preocupações ligadas a questões emocionais das famílias, retrocessos na aprendizagem dos alunos e possível aumento da evasão escolar conforme sinalizado no Parecer CNE/CP $n^{0}$ 9/2020:

Dificuldade para reposição de forma presencial da integralidade das aulas suspensas ao final do período de emergência, com o comprometimento ainda do calendário escolar de 2021 e, eventualmente, também de 2022; retrocessos do processo educacional e da aprendizagem aos estudantes submetidos a longo período sem atividades educacionais regulares, tendo em vista a indefinição do tempo de isolamento; danos estruturais e sociais para estudantes e famílias de baixa renda, como stress familiar e aumento da violência doméstica para as famílias, de modo geral; abandono e aumento da evasão escolar. (CNE, 2020, p.3) 
Em complemento às ações governamentais ligadas ao ano letivo brasileiro de 2020, é publicada também a Lei $N^{0} 14.040$, de 18 de agosto de 2020, a qual estabeleceu normas educacionais excepcionais a serem adotadas durante o estado de calamidade pública.

Com o objetivo de garantir o atendimento escolar aos alunos da educação básica, considerado essencial, foi autorizado em caráter excepcional a utilização de atividades pedagógicas não presenciais, durante o período de duração das restrições sanitárias. O Parecer CNE/CP No: 9/2020 sinalizou que essas atividades poderiam ser mediadas ou não por Tecnologias Digitais de Informação e Comunicação (TDIC), considerando a impossibilidade destas não serem possíveis de ocorrer em alguma região, por qualquer que seja o motivo. (Parecer CNE/CP No: 9, 2020)

\section{Diferenças entre educação a distância e aulas remotas}

No tocante à classificação do que foi adotado como medida de manutenção das atividades escolares considera-se cabível uma reflexão quanto aos termos: Educação a Distância (EAD), Educação Presencial e Aulas Remotas para melhor entendimento do que representam, pois, durante a quarentena provocada pela COVID-19, o que antes se apresentava separado - a modalidade de ensino presencial de um lado e a modalidade de ensino a distância por outro - a "opção do ensino remoto" como solução temporária e emergencial, tendo por finalidade minimizar os impactos nos processos de ensino e aprendizagem em tempos de crise, estas modalidades se misturaram. Ressalta-se que há diferenças entre a modalidade Educação a Distância e a modalidade presencial institucionalmente constituída ou aula remota compreendida, neste contexto, como uma medida provisória. Por isso a necessidade de apresentar neste estudo os conceitos de Educação a Distância, Educação Presencial e Aulas Remotas.

O Decreto No 9.057 de 2017, no que tange à caracterização da educação a distância, a classifica como modalidade educacional que faz uso de tecnologias de informação e comunicação, devendo existir profissionais qualificados para o exercício da modalidade, bem como políticas de acesso e de acompanhamento compatíveis, o que conduz à interpretação de que devem ser aspectos simultâneos e que permitirão o desenvolvimento de atividades educativas por estudantes e profissionais da educação.

Art. 10: considera-se educação a distância a modalidade educacional na qual a mediação didático-pedagógica nos processos de ensino e aprendizagem ocorra com a utilização de meios e tecnologias de informação e comunicação, com pessoal qualificado, com políticas de acesso, com acompanhamento e avaliação compatíveis, entre outros, e desenvolva atividades educativas por estudantes e profissionais da educação que estejam em lugares e tempos diversos. (Decreto, 2017, s/p)

A educação a distância começou por volta de 1.850 em vários países da Europa. Ela existe desde o século XIX, ocorrendo por meio de correspondência. Tinha como objetivo oferecer educação a todos os que, por um motivo ou outro, não podiam chegar até uma escola, seja por necessidades especiais (cegueira, surdez, incapacidade física de se locomover, entre outras limitações), seja por não poderem se afastar de suas casas em razão do compromisso de cuidar de familiares de idade avançada ou de crianças. Neste sentido, a educação a distância cumpre a sua função 
de "inclusão social" pela aprendizagem à distância. Justamente pela possibilidade de oferecer educação para além dos muros escolares, das instituições tradicionalmente constituídas (Litto, 2010).

Fazendo uma rápida linha do tempo sobre o percurso da EAD de 1850 a 1900, com base nos estudos de Litto (2010), durante os primeiros cinquenta anos, o meio de acesso ao conhecimento era por meio do material impresso, levado até o aprendiz pelo correio. Os estudantes estudavam o material que recebiam, realizavam os exercícios e o trabalho final e reenviavam aos professores que corrigiam e davam as devolutivas, e os alunos recebiam os feedbacks. Tudo isso via correio.

Já o cinema, começou a ser usado para aprendizagem à distância, na primeira década do século XX. Escolas, universidades e empresas criaram cursos inteiros em filmes que eram distribuídos nacional e internacionalmente. Cursos por meio do rádio passaram a ser levados na terceira e quarta décadas do século XX. O mesmo aconteceu a partir da década de 50, com o advento e popularização da televisão.

A educação à distância (EAD) no Brasil tem marcado sua história de sucessos, levando educação, através da mídia impressa, do rádio, da televisão e agora por meio da internet, a todos os cantos do mundo. Por todo este seu histórico, na pandemia ela evidenciou o seu potencial.

Quanto às diferenças, na modalidade de EAD, os estudantes não contam com a presença física do/a professor/a. As aulas são por meio de recursos digitais disponíveis em plataformas online ou os chamados ambientes virtuais de aprendizagem. Estas plataformas dispõem de ferramentas de comunicação para postar avisos, criar espaços de discussões por meio de fóruns, enviar mensagens, calendários para a gestão das atividades; ferramentas de gestão de conteúdos para a criação e incorporação de novos conteúdos, de tarefas e atividades para a avaliação dos estudantes; ferramentas de gestão da aprendizagem; relatórios para acompanhar a evolução e estatística dos estudantes. Todo o processo de ensino e aprendizagem nesta modalidade é acompanhado pela plataforma. E o perfil do estudante nesta modalidade é mais independente e autônomo. Disciplina também é uma das posturas requeridas para o estudante não acumular os estudos e cumprir com a agenda escolar, entrega das atividades e realizações das avaliações. É uma modalidade de ensino institucionalmente e legalmente constituída, assim como a modalidade presencial.

Já na modalidade de ensino presencial, há a necessidade da presença física, do diálogo, da interação e convívio entre professores e estudantes. O perfil do estudante é mais dependente do/a professor/a dependendo do nível de ensino, em virtude de estar acostumado a ouvir explicações sobre os conteúdos, a tirar dúvidas, a fazer as atividades sob a orientação e com a presença face a face do/a professor/a mediador/a. Mesmo que o/a professor/a disponibilize recursos online para realização de alguma atividade extra-classe, o mesmo é explicado no encontro presencial a fim de que os estudantes consigam realizar com segurança a atividade proposta, mesmo quando estiverem sozinhos. Neste sentido, a modalidade de ensino presencial pode e deve contar com as metodologias do ensino a distância, em um processo de "hibridização" (Moran, 2015), contando também com atividades online. 
Diante destes esclarecimentos, utilizar-se de estratégias de aprendizagem de ensino online, envolvendo texto, imagem e som, como atividades complementares na modalidade de Ensino presencial, e, principalmente nesta situação atípica, de contexto pandêmico, com aulas sendo ministradas remotamente são um dos caminhos a serem vislumbrados mesmo pós-pandemia, pois o ensino presencial e a EaD não são modalidades opostas, mas complementares entre si e uma e outra, de acordo com as suas características, tempos e espaços podem favorecer e dar maior qualidade aos processos educativos. Quanto ao conceito de aulas remotas, considera-se aquelas realizadas por meio de normativas da educação presencial, que permitem a continuidade ou complementação da escolarização com uso de recursos tecnológicos digitais, porém com indivíduos (professores e alunos) em locais distintos. Neste sentido, utilizaremos o termo aula remota. No entanto, estaremos nos referindo à modalidade de ensino presencial, em virtude da circunstância de pandemia.

\section{Metodologia}

Para realização deste estudo, adotou-se pesquisa exploratória por meio da abordagem qualitativa. O corpus desta pesquisa é formado por professores representantes das cinco regiões brasileiras que atenderam ao convite à pesquisa e responderam prontamente o instrumento, totalizando 39 participantes atuantes em escolas públicas e privadas.

O instrumento utilizado nesta pesquisa foi o questionário on-line (survey eletrônico) para alcançar o objetivo central proposto com o maior número de participantes possíveis. Ele foi criado no Google Forms e sua estrutura apresenta três seções: dados sociodemográficos e relacionados à prática educacional dos pesquisados; conhecimento e utilização de tecnologias por parte dos investigados durante o ensino remoto; percepção dos professores em relação aos desafios e as aprendizagens adquiridas com o ensino remoto.

Para a análise dos dados produzidos, utilizou-se o processo de análise de conteúdo baseado em Bardin (2002).

\section{Resultados e discussão}

Diante do contexto atual pandêmico ocorrido, na segunda década do século $X X I$, inúmeros dos recursos tecnológicos já incorporados tanto no computador quanto nos smartphones tornaram-se evidenciados na maioria das práticas educacionais, por parte dos professores das escolas públicas e privadas, trazendo consigo mais interatividades aos processos de ensino e aprendizagem. Eles atuaram como fontes de auxílio aos professores em momentos de pandemia, cujo ensino presencial passou, emergencialmente, a ser ministrado remotamente.

As tecnologias digitais de informação e comunicação (TDIC) possibilitaram caminhos, luzes para os professores darem continuidade aos seus trabalhos. No entanto, por um lado, muitos foram os desafios enfrentados, mas também por outro, surgiram também os aprendizados. Daí a importância de conhecer a percepção dos docentes que vivenciaram a experiência de ministrarem aulas por meio da utilização de tecnologias em rede. 
Para tanto, iniciamos com a apresentação dos dados sociodemográficos e relacionados à prática educacional do público participante da pesquisa, para então apresentar a percepção dos professores quanto aos desafios e aprendizados com o ensino remoto.

\subsection{Dados sociodemográficos e relacionados à prática educacional dos pesquisados}

Todos os participantes da pesquisa são professores que atuam em escolas tanto da área pública $(66,7 \%)$, quanto da privada (33,3\%). A maioria é do gênero feminino (87,2\%) e estão na faixa etária entre 31 a 40 anos $(61,5 \%)$, com experiência docente há mais de 11 anos. Sendo que essa atuação é predominantemente no Ensino Fundamental - Anos Finais com um percentual de $41 \%$ registrados. Seguido do Ensino Médio com 23,1\%, conforme a tabela abaixo:

Tabela 1 - Identificação pessoal/profissional

\begin{tabular}{lll}
\hline Identificação pessoal/profissional & \\
\hline Professores da Educação Básica & Pública & $66,7 \%$ \\
\cline { 2 - 3 } Gênero & Particular & $33,3 \%$ \\
& Masculino & 18,2 \\
\hline \multirow{2}{*}{ Idade } & Feminino & $87,2 \%$ \\
& 31 a 40 anos & $61,5 \%$ \\
\hline \multirow{2}{*}{ Experiência profissional } & 41 a 50 anos & $25,6 \%$ \\
& 18 a 30 anos & $7,7 \%$ \\
& Há menos de 5 anos & $15,4 \%$ \\
& Entre 5 a 10 anos & $15,4 \%$ \\
\hline Segmento de atuação & Entre 11 a 20 anos & $48,7 \%$ \\
& Há mais de 20 anos & $20,5 \%$ \\
& Ensino Fundamental - Anos Finais & $41 \%$ \\
\cline { 2 - 3 } & Ensino Médio & $23,1 \%$ \\
\hline
\end{tabular}

Fonte: Elaborada pelas autoras, com base nos dados do questionário on-line: I - Identificação pessoal e profissional.

Consoante a tabela 1 , constata-se que são professores com bastante tempo de experiência no exercício da docência. Eles estão na margem dos 2/3 (dois terços) do perfil correspondente aos chamados "imigrantes digitais" (Palfrey e Gasser, 2011), cuja formação obtida foi anterior ao final das últimas décadas do século XX, marcado pela revolução propiciada pela chegada das tecnologias digitais de informação e comunicação. Neste sentido, estes professores tiveram de aprender a lidar com as tecnologias, incorporando-as no seu cotidiano. Tal qual está ocorrendo neste período de confinamento social, cujo contexto, porém, pegou a todos de surpresa e sem a formação necessária para uma atuação totalmente em rede em relação aos processos de ensino. 
Estudos realizados por Alves, Santos e Gonçalves (2017) - com base em artigos publicados em 2003 a 2016 - demonstram que apesar de diferentes políticas, programas governamentais e projetos criados e implementados, em âmbito federal, municipal e estadual, para a formação quanto ao uso das tecnologias digitais de informação e comunicação nas práticas pedagógicas, a proporção de professores que fazem uso ainda é pouco considerável, limitado, bem como pouco inovador, apesar de há muito tempo no meio educacional já se defender o quanto a tecnologia digital é necessária e importante para os processos de ensino e aprendizagem. Ainda assim, muitos dos profissionais em exercício de suas atividades educativas não se apropriaram dos referidos conhecimentos ou não se adaptaram à utilização destes recursos, mesmo com os movimentos e transformações digitais que a todo momento o mundo contemporâneo vivencia.

O uso da tecnologia digital integrado ao processo de ensinagem, em muitas escolas brasileiras das redes públicas e privadas, ainda não representa a realidade. E mais que de repente a pandemia COVID-19 exigiu, de maneira cruel, que os professores no Brasil se apropriassem do uso de tecnologias digitais como condição sine qua non para continuar trabalhando neste momento. Champaoski e Mendes (2017), ao realizar uma pesquisa sobre o uso significativo das tecnologias digitais no processo de ensino e aprendizagem identificaram que:

A inserção das tecnologias digitais no cotidiano escolar ainda é, ao mesmo tempo, um fator de aproximação e de distanciamento, e por isso mesmo um grande desafio para os professores, visto que, embora muitos recursos dessas tecnologias estejam acessíveis aos estudantes e professores, pouco movimento se percebe para integrá-los nas práticas pedagógicas de ensino e aprendizagem no cotidiano escolar. (Champaoski e Mendes, 2017, p. 70)

Os professores precisaram aprender a lidar com determinadas tecnologias, a desenvolver repentinamente habilidades próprias de professores que já trabalham com educação à distância por meio de videoaulas, porém sem tempo para se preparar e conhecer melhor como poderiam explorar determinadas tecnologias para fazer delas o seu melhor uso pedagógico e de forma crítica.

Na educação básica, o espaço físico da sala de aula, onde a comunicação entre professores e alunos ocorria presencialmente, passou a ser um espaço virtual, um novo ambiente de comunicação, com o uso de outros recursos tecnológicos para lá dos tradicionalmente constituídos.

Possivelmente, para alguns professores já com experiência em docência online, o processo de mudança do ambiente escolar presencial para o virtual possa ter ocorrido com certa tranquilidade. Para a grande parcela de professores, é razoável acreditar que esta inovação escolar, totalmente mediada por tecnologias digitais, embora tenha se apresentado como uma solução pedagógica para o momento, ela foi marcada por inúmeras dificuldades e aprendizagens tanto para a gestão escolar e equipe pedagógica, quanto para os alunos e seus familiares que, em meio a essas mudanças, também tiveram que aprender a se reposicionar como orientadores dos alunos (seus filhos). 
Os problemas formativos continuam. Dessa forma demonstrandoaimportância cada vez mais de investimentos em processos formativos, pois a margem de professores "nativos digitais" (Palfrey e Gasser, 2011) e no exercício da profissão após o surgimento da Internet é somente de 7,7\%, em nível nacional, conforme Tabela 1, anteriormente apresentada. Diante desses dados, ficam claros os desafios que os professores (quase $90 \%$ da rede pública e privada do país) tiveram de enfrentar ao terem sido submetidos abruptamente ao trabalho com os seus estudantes por meio e auxílio dos recursos tecnológicos. Perpassados, sobretudo, por diversos problemas no que se refere a condições de acesso aos dados e materiais por parte do alunado, revelando a exclusão social dos marginalizados e o poder do acesso à educação por parte dos que dispõem dos recursos tecnológicos, enaltecendo as empresas fornecedoras de dados da Internet e o capitalismo selvagem.

Pelo gráfico 1 abaixo apresentado, constata-se que a Internet residencial foi a mais utilizada durante o tempo de confinamento e distanciamento social, até mesmo em virtude das facilidades de uma rede: velocidade, praticidade de acesso em qualquer canto da casa e ainda distribuição para outros dispositivos. Além da economia, pois planos para celulares não iriam atender aos outros aparelhos disponíveis na residência.

Gráfico 1. Acesso a Internet

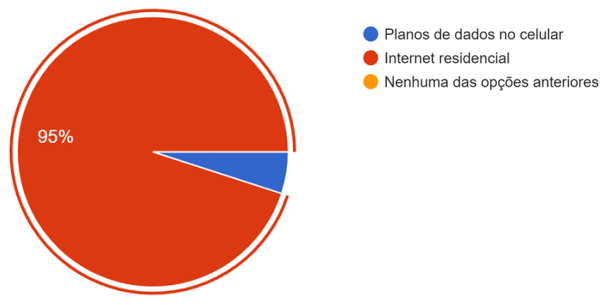

Fonte: Elaborada pelas autoras, com base nos dados colhidos no questionário on-line: I - Google Form.

Apesar de o Brasil ser um país com uma extensão territorial imensa, a abrangência deste estudo contemplou as cinco regiões brasileiras. Situação possível devido às tecnologias envolvidas: email e questionário on-line. Segue a representatividade nacional:

Gráfico 2. Representatividade dos participantes por Estados
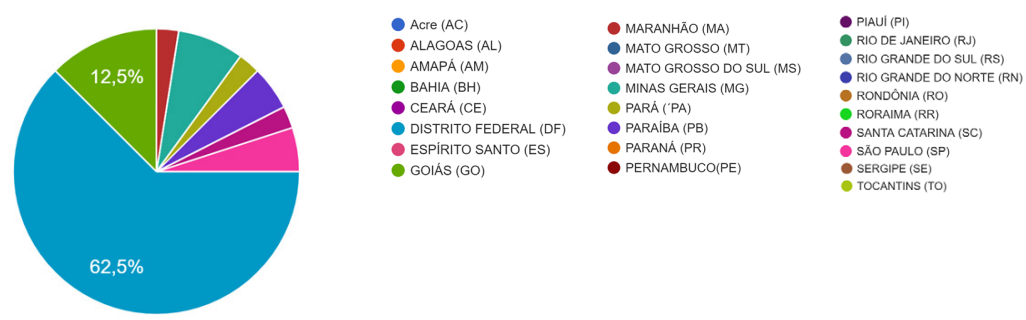

Fonte: Elaborada pelas autoras, com base nos dados do questionário on-line - Google Form. 
Apesar da diversidade territorial brasileira, os problemas entre os estados se igualam no que se refere aos desafios proporcionados com a experiência vivenciada pelos professores por meio do ensino remoto: a formação insuficiente dos próprios professores, a falta de recursos tecnológicos por parte dos estudantes e/ou suporte técnico para atendimentos às dificuldades dos professores, a falta de acesso à internet, a dificuldade de controlar os estudantes na Internet para a realização das atividades propostas, principalmente sem a presença física e mediadora do/a professor/a durante o desenvolvimento das atividades, visto que a lógica estabelecida pelas TDICs implica trabalho em rede, com colaboração e autonomia. Sabendo-se que na educação básica essa autonomia está em construção. Os estudantes ainda são dependentes de outros mais experientes para avançar em seus próprios processos construtivos de conhecimento.

Fazendo uma análise acerca dos recursos que os professores dispunham para acessar a plataforma e ministrar o seu trabalho online, entre quatro dispositivos mencionados, dois sobressaíram: notebook com 89,7\% e smartphones com 69,2\%, ficando o computador de mesa com 10,3\% e por último, o tablet, com 7,7\%. Esse panorama aponta que os professores pesquisados possuem equipamentos mais modernos e com mobilidade.

O primeiro recurso da lista (o notebook) traz consigo vários programas que auxiliam os professores na organização e planejamento de suas aulas remotas: escrever textos, criar planilhas, fazer apresentações de slides, navegar em sites, organizar arquivos, imagens, vídeos, músicas com o conforto da tela maior que a de outros. O segundo dispositivo (o smartphone) atrai pelo acesso a redes sociais, locais em que a maioria de seus estudantes se encontram. E ainda pela facilidade de baixar aplicativos divertidos com foco educacional que podem atender em alguns aspectos pedagógicos da matéria a ser ministrada.

Quanto ao conhecimento e utilização das tecnologias, por parte dos professores pesquisados, verificou-se, conforme os dados, que a maioria dos professores se veem ou no nível básico (39,4\%) ou intermediário (42,4\%). Ou seja, os professores são sujeitos epistêmicos, em constante busca pelo conhecimento e saberes para atendimento às próprias necessidades reais e atuais. E o momento pandêmico revelou e fez aflorar o potencial já até reconhecido por parte dos professores no que se refere a certo conhecimento em relação a vários recursos tecnológicos. No entanto, adormecido em função da falta de confiança para colocar os saberes já anteriormente apreendidos em contextos formativos.

A pandemia, neste sentido, possibilitou aos professores, mesmo a "fórceps", de se reinventarem quanto ao fazer pedagógico, tendo as tecnologias como aliadas auxiliares. E as estratégias utilizadas pelos professores no contexto de confinamento social foram as mais variadas possíveis para manter maior proximidade com os estudantes e continuidade aos processos de ensino e aprendizagem.

Dentre as onze estratégias apresentadas, o vídeo (86,1\%) destacou-se como a mais utilizada pelos professores no desenvolvimento de suas atividades pedagógicas online. Seguida da exposição dialogada (58,3\%), slides (50\%) eáudio $(47,2 \%)$. Vejamos: 
Gráfico 3. Estratégias adotadas pelos professores durante as aulas online

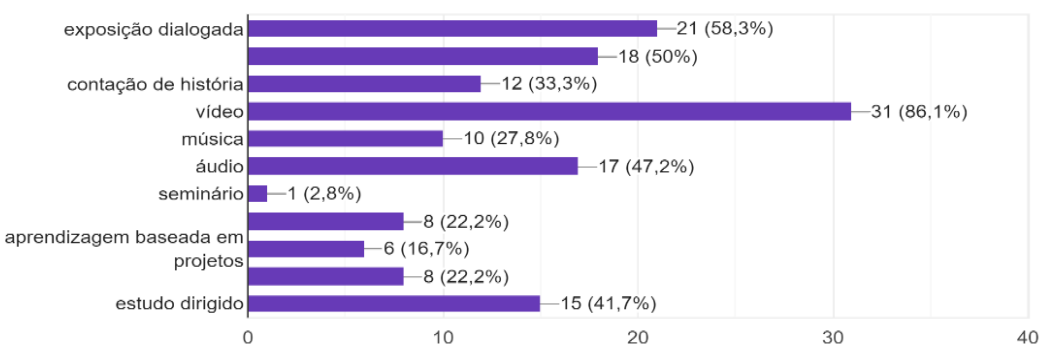

Fonte: Elaborada pelas autoras, com base nos dados do questionário on-line: I - Identificação pessoal e profissional. Google Form.

A opção pelos vídeos demonstra que os professores pesquisados desenvolveram estratégias para criar no trabalho meios facilitadores de manter a comunicação e a aprendizagem dos estudantes. De acordo com Alencar, Bruno-Faria e Fleith (2010, p. 138) "estratégias para criar no trabalho se refere aos esforços empreendidos pelo indivíduo para favorecer a criação de ideias novas e úteis na resolução de problemas de trabalho". Os autores destacam ainda que essas estratégias são derivadas das experiências de cada profissional e de habilidades cognitivas prévias.

Neste aspecto, infere-se que o/a professor/a transpôs as estratégias presenciais de sala de aula utilizadas cotidianamente para o ensino remoto. Nesta questão, no entanto, é fundamental analisar o contexto em que os pesquisados foram inseridos, abruptamente e em um curto espaço de tempo. O que torna plausível essa prática inicial, em função do que já se tem segurança em relação ao fazer pedagógico para uma situação nova e emergente, transpondo o conhecimento já apreendido para um ainda em processo de reorganização. O que não significa que este contexto e prática sejam permanentes à medida que o professor for se acomodando e se confortando com o real contexto, para então poder recriar e ressignificar a própria prática, a partir do novo instaurado. Ou melhor, dizendo, ao "novo normal", para aos poucos ir significando o espaço pedagógico em conformidade com as circunstâncias dessa realidade em que se situam, bem como irem se apropriando e gerando novos sentidos e significados ao fazer pedagógico, para uma nova adaptação à realidade educativa pós-pandêmica, pois jamais seremos os mesmos, jamais a escola será a mesma, em virtude das mudanças mais profundas na vida em sociedade, nos hábitos de consumo e no mercado de trabalho, provocadas pela crise instaurada pela COVID19.

\subsection{Percepção dos professores quanto aos desafios e aprendizados com o ensino remoto}

\subsubsection{Desafios}

No que concerne aos desafios apresentados pelos respondentes deste estudo, destaca-se no quadro abaixo suas respostas classificadas em quatro grupos: recursos tecnológicos, metodologia de ensino, comportamento dos alunos e questões pessoais dos professores. 
Tabela 2. Desafios

\begin{tabular}{|c|c|c|c|}
\hline $\begin{array}{c}\text { Desafios relacionados } \\
\text { a recursos } \\
\text { tecnológicos }\end{array}$ & $\begin{array}{c}\text { Desafios relacionados à } \\
\text { metodologia de ensino }\end{array}$ & $\begin{array}{c}\text { Desafios } \\
\text { relacionados a } \\
\text { comportamento dos } \\
\text { alunos }\end{array}$ & $\begin{array}{c}\text { Desafios relacionados a } \\
\text { questões pessoais dos } \\
\text { professores }\end{array}$ \\
\hline $\begin{array}{l}\text { - Dificuldade dos } \\
\text { alunos em relação } \\
\text { ao acesso à internet } \\
\text { de boa qualidade e } \\
\text { recursos tecnológicos } \\
\text { necessários (aparel- } \\
\text { hos eletrônicos). } \\
\text { - Ausência de cursos } \\
\text { de capacitação para } \\
\text { esclarecer dúvidas } \\
\text { sobre o Google } \\
\text { Classroom. } \\
\text { - Ausência de apoio } \\
\text { da instituição com } \\
\text { relação à disponibi- } \\
\text { lização de recursos } \\
\text { como internet e } \\
\text { notebook. } \\
\text { - Uso de tecnologia e } \\
\text { recursos alheios à } \\
\text { sala de aula. } \\
\text { - Aprender a usar } \\
\text { várias ferramentas } \\
\text { em pouco tempo e } \\
\text { lidar com a agonia de } \\
\text { ministrar aulas para } \\
\text { alunos com câmeras } \\
\text { desligadas. } \\
\text { - Gravar e editar os } \\
\text { vídeos. }\end{array}$ & 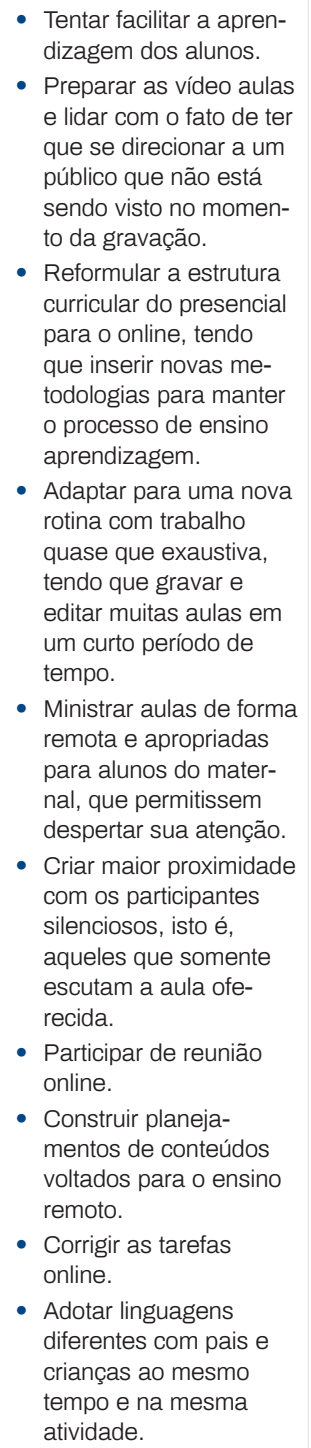 & $\begin{array}{l}\text { - Distância física dos } \\
\text { alunos e entre os } \\
\text { alunos. } \\
\text { - Retorno das ativida- } \\
\text { des propostas. } \\
\text { - Alunos sem interes- } \\
\text { se pelas atividades } \\
\text { online. } \\
\text { - Falta de comprometi- } \\
\text { mento dos alunos. } \\
\text { - Fazer com que os } \\
\text { alunos estudem e } \\
\text { respondam as ativi- } \\
\text { dades. } \\
\text { - Contato telefônico } \\
\text { com os alunos. } \\
\text { - Convencer os alunos } \\
\text { a acordar cedo para } \\
\text { a aula ao vivo no } \\
\text { Google Meet. } \\
\text { - Dificuldade dos alu- } \\
\text { nos em se concentrar } \\
\text { nas aulas online. }\end{array}$ & $\begin{array}{l}\text { - Organizar o tempo de } \\
\text { trabalho. } \\
\text { - Manter a motivação para } \\
\text { realizar o trabalho e ao } \\
\text { mesmo tempo buscar } \\
\text { formas de estimular os } \\
\text { alunos. } \\
\text { - Superar a timidez. } \\
\text { - Cativar os estudantes. } \\
\text { - Dificuldade para adotar } \\
\text { uma rotina de trabalho } \\
\text { no ambiente residencial. } \\
\text { - Paciência com os pais } \\
\text { que desejam sanar dúvi- } \\
\text { das a qualquer momento } \\
\text { do dia e da semana. }\end{array}$ \\
\hline
\end{tabular}

Fonte: Elaborada pelas autoras, com base nos dados do questionário on-line - Google Form

Os resultados apresentados na Tabela 2 acima demonstram que os desafios que apresentaram mais diversidade de respostas foram aqueles ligados à metodologia de ensino, comportamento dos alunos e recursos tecnológicos, respectivamente. 
Nota-se que a experiência de vivenciar o trabalho docente de forma remota exigiu do profissional revitalizar suas práticas de ensino e aprender a lidar com o distanciamento dos alunos não apenas físico, mas também com o baixo envolvimento dos mesmos nas atividades propostas.

A respeito dos desafios classificados quanto à metodologia de ensino, vale mencionar Coll e Monereo (2010, p. 31), os quais sinalizam que "[...] a imagem de um professor transmissor de informação, protagonista central das trocas entre seus alunos e guardião do currículo começa a entrar em crise em um mundo conectado pelas telas de computador." Ou seja, os itens apresentados revelam a dificuldade de transferir a mesma qualidade de uma docência presencial para uma docência online, com uso de recursos tecnológicos pouco explorados anteriormente.

No que concerne aos desafios ligados a recursos tecnológicos, evidencia-se que alguns docentes passaram por dificuldades tanto com relação ao acesso de recursos, quanto com a utilização de determinadas ferramentas consideradas por eles necessárias para o momento. Preensky apud Champaoski e Mendes (2017, p. 56) destaca que "no contexto das tecnologias digitais, o/a professor/a vive a experiência singular de se encontrar em papel dúbio na aprendizagem, pois é mediador/a e também aprendiz digital, ou ainda um/a "imigrante digital".

Destaca-se o fato de alguns docentes terem buscado soluções sozinhos para resolver problemas de acesso a internet e computador. As respostas demonstram que houve negligência de algumas escolas por não ter oferecido o devido apoio ao docente no que tange ao acesso a recursos mínimos.

Outro ponto que despertou atenção foram os desafios relacionados ao comportamento dos alunos. Nota-se, pela fala dos docentes, que os estudantes estavam pouco motivados e/ou tiveram dificuldades em se adaptar com o novo formato de aula adotado.

A respeito dos desafios relacionados a questões pessoais dos professores, destaca-se que estas tiveram pouca expressividade, porém não menos importância. Notou-se que os docentes apresentaram dificuldades em organizar uma rotina de trabalho residencial, de controlar a ansiedade e expectativa, colocando em risco a motivação de alguns desses profissionais, o que pode ser melhor visualizado ao analisar o Gráfico 4 a seguir:

Gráfico 4. Sentimentos por parte dos professores durante o período de pandemia

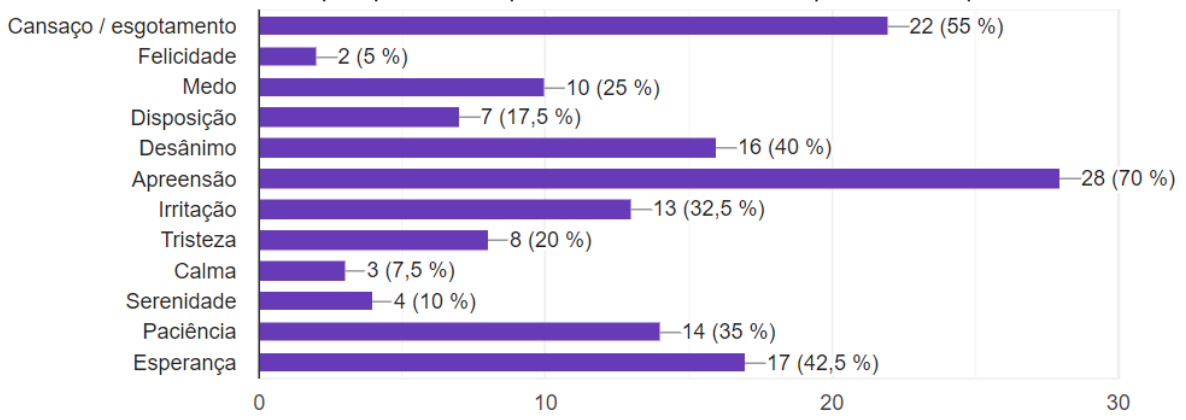

Fonte: Elaborada pelas autoras, com base nos dados do questionário on-line - Google Form. 
O gráfico 4 acima deixa visível sentimentos que mexeram com o emocional de muitos docentes. Apreensão (70\%), cansaço/ esgotamento (55\%), desânimo (40\%) acentuam-se, demonstrando que as aulas online trouxeram uma carga de trabalho maior do que o esperado, entrelaçado por momentos de constantes inquietações pelo contexto incerto e inseguro provocado pela pandemia. Porém, a esperança (42,5\%) emerge também como luz em tempo de escuridão.

\subsubsection{Aprendizados}

Quanto aos aprendizados no momento de confinamento e aulas remotas, a partir dos relatos descritos, três categorias emergiram: recursos tecnológicos, interação entre pares, tempo e organização do espaço. A tabela 3 apresentada a seguir evidencia as categorias encontradas por meios de critérios de proximidade de conteúdo.

Tabela 3. Aprendizados

\begin{tabular}{|c|c|c|}
\hline $\begin{array}{l}\text { Aprendizagens quanto aos } \\
\text { recursos tecnológicos }\end{array}$ & $\begin{array}{l}\text { Aprendizagens quanto } \\
\text { aos meios de interação } \\
\text { entre professores, alunos e } \\
\text { comunidade escolar }\end{array}$ & $\begin{array}{c}\text { Aprendizagens quanto ao poder } \\
\text { do tempo e da organização no seu } \\
\text { cotidiano }\end{array}$ \\
\hline $\begin{array}{l}\text { - Uso de tecnologias antes } \\
\text { desconhecidas por mim e no- } \\
\text { vas metodologias de ensino. } \\
\text { - Usar o Google Sala de Aula e } \\
\text { alguns Apps da Google. } \\
\text { - Aprender a usar novas tec- } \\
\text { nologias digitais. Desenvolver } \\
\text { atividades mais lúdicas. } \\
\text { - Mais domínio de ferramentas } \\
\text { eletrônicas e melhoria no uso } \\
\text { de aplicativos. } \\
\text { - Aprender a lidar com ino- } \\
\text { vações tecnológicas e buscar } \\
\text { meios e recursos alternativos } \\
\text { para levar o aprendizado ao } \\
\text { aluno. } \\
\text { - Habilidade tecnológica. }\end{array}$ & $\begin{array}{l}\text { - Proximidade afetiva com os } \\
\text { pais, mesmo a distância, com- } \\
\text { preensão, didática e desen- } \\
\text { voltura em realizar cada vídeo } \\
\text { elaborado. } \\
\text { - Melhorar no planejamento para } \\
\text { compreensão do aluno. } \\
\text { - Interação virtual. } \\
\text { - Há várias formas de se comu- } \\
\text { nicar... } \\
\text { - Posso dizer que aprendi muito } \\
\text { a acreditar nos pequenos ... } \\
\text { - Interação com pessoas e pro- } \\
\text { fissionais de fora do ambiente } \\
\text { escolar (convidados e partici- } \\
\text { pantes externos)... }\end{array}$ & $\begin{array}{l}\text { - Organização do tempo e espaço } \\
\text { de casa. } \\
\text { - Autoconhecimento tive tempo para } \\
\text { rever questões pessoais e profissio- } \\
\text { nais/ utilizei poesias... } \\
\text { - Não controlo a minha vida. } \\
\text { - Durante o período da pandemia } \\
\text { aprendi a lidar de maneira mais } \\
\text { rápida e ágil com os recursos tec- } \\
\text { nológicos os quais não tinha conhe- } \\
\text { cimento... } \\
\text { - "Regras e horários. }\end{array}$ \\
\hline
\end{tabular}

Fonte: Elaborada pelas autoras, com base nos dados colhidos no questionário on-line - Google Form.

Ao analisar os resultados quanto aos aprendizados, pode-se notar um processo complementar aos desafios elencados por esse grupo. Ou seja, o momento foi de constantes desafios, mas os mesmos foram impulsionadores de aprendizagens para lidar com os recursos tecnológicos, as metodologias de ensino e os comportamentos diversos de alunos, pais e ainda com as próprias questões pessoais e emocionais dos pesquisados.

Os termos em negrito destacam as referências que permearam as categorias. A primeira categoria refere-se quanto aos avanços e descobertas de recursos tecnológicos. Os vocábulos: usar, aprender, buscar, domínio, encontrados nas frases refletem um ser atento a sua atuação na busca de se apropriar dos recursos tecnológicos frente ao contexto atual advindo pela pandemia, o que remete a Lévy (2010, p. 28) ao dizer que a qualidade desse processo imbuído das relações humanas é mais importante que particularidades das ferramentas. A virtualização da informação 
e da comunicação mencionadas por Lévy (2010) estimula a inteligência coletiva e ao se ver sozinho, cumprindo o isolamento social é plausível notar ainda um professor inexperiente ou inseguro neste universo tecnológico, um "aprendiz digital" (Palfrey e Gasser, 2011) com base nas expressões elencadas pelos pesquisados: antes desconhecidas, novas metodologias, desenvolver atividades, melhoria no uso. Porém, despertou a colaboração nos mesmos, além de maior interatividade.

A segunda categoria consiste nos meios de interação entre professores, alunos e comunidade escolar. O recorte exposto na tabela acima evidencia um professor ávido em se comunicar mais e claramente com seus alunos, pais e comunidade em geral. Esta categoria permite retomar o processo de ensino e aprendizagem, pois "a aprendizagem é um processo de construção do discente que elabora os saberes graças e por meio das interações." (Freire, 2011, p. 84). A busca da promoção de novas interações, agora, digitais, apresenta um novo cenário comunicacional para o/a professor/a e pais. Todavia, não tão distante do nosso aluno rodeado de linguagens digitais no seu cotidiano, talvez agora as aulas possam aproximá-los mais da vida real ao do âmbito educacional.

$\mathrm{Na}$ categoria relacionada quanto ao poder do tempo e da organização no seu cotidiano, percebe-se que os desafios inicialmente expressos em sentimentos de apreensão devido ao momento pandêmico junto com o cansaço de todas as atividades, concederam a esse grupo um olhar acerca desses dois aspectos: tempo e organização, para poder lidar não só com o seu trabalho, mas também com sua vida pessoal no mesmo espaço. Autoconhecimento, regras, horários, agilidade evidenciaram-se. Segundo Ribeiro (2020, p. 77),

As rupturas sociais vão acontecer em um ritmo tão acelerado que mal haverá tempo para digeri-las, ou de decidir onde nos encontramos no mundo: sob um ponto de vista da tecnologia, ressignificamos fronteiras, territórios e culturas.

Essa ressignificação foi fundamental em vários setores, principalmente na área educacional tão fechada dentro dos muros da escola. Redefiniu-se as fronteiras, ou melhor, romperam-nas.

Enfim, a disparidade social afetou todo o Brasil, demonstrando o quão a tecnologia está longe de fazer parte da realidade dos estudantes e professores, como instrumento potencial para o desenvolvimento tanto no aspecto humano quanto social. E a escola cada vez mais longe da posse de um aparato tecnológico, como o da Internet e de seu valor potencial em poder contribuir para aprendizagens mais voltadas à autoria docente e discente, com saúde e equilíbrio emocional, aliadas ao aprofundamento pela pesquisa, ao trabalho colaborativo, aos processos dialógicos intersubjetivos, à educação continuada, como assim sugere Moran (2001) sem, necessariamente, os sujeitos do ensino e da aprendizagem estar face a face, de modo presencial.

É importante considerar que o acesso às informações, não é sinônimo de acesso ao conhecimento. Mas é fato que com a pandemia, os processos de ensino e aprendizagem se desmistificaram como processos apenas nos contextos das salas de aula convencionais, indo-se além dos muros que a separam da sociedade. 
O ciberespaço como assim considerado por Castells (2001) passa a ser o mais novo e complexo espaço global para ações sociais e educacionais, apontando para o surgimento de novos tempos, novos espaços por meio de um ensino híbrido (misturado) e não mais somente configurado nos modos tradicionalmente constituídos. A escola finalmente, em tempos pandêmicos, se desvincula do chão para o espaço, tornando-se um dos nós da grande rede mundial de computadores, deixando prevalecer como mais um dos grandes marcos na história da Educação, instaurados e demarcados pela COVID-19.

Sendo assim, e diante do cenário pandêmico, é oportuno considerar segundo Demo (2009), Pretto (2008) e Morin (2010), que já não é mais possível, mesmo já anterior e após a pandemia, pensar em educação sem se utilizar do potencial oferecido pelas tecnologias em rede por parte dos envolvidos na práxis pedagógica (professores e estudantes). É preciso repensar os espaços educativos a partir de um novo paradigma tecnológico, compreendendo a escola como "mediadora entre educação e novas instrumentalizações" (Almeida, 2014, p. 38), e não como um espaço estático, mas rico de possibilidades dos sujeitos envolvidos na práxis pedagógica de estarem interconectados e integrados com a realidade que os circundam.

Neste sentido, os dados apresentados neste contexto, só reforçam o que Araújo (2017, p.152-153) já havia constatado em sua pesquisa: a necessidade de investimentos em infraestruturas tecnológicas e em cursos de formação continuada para todos os professores do Brasil - por meio da esfera federal -, com vistas à atualização dos professores, digitalmente, tanto em nível inicial quanto continuada. Haja vista que o processo formativo ao longo da vida apresenta-se como "um dos principais instrumentos mediadores e de aproximação entre escola e cultura, bem como para inclusão dos professores, apropriação dos recursos tecnológicos e a possibilidade de utilização em sala de aula, pedagogicamente, com a necessária fluência tecnológica".

\section{Considerações finais}

Quanto aos desafios vivenciados pelos docentes e considerando os recursos tecnológicos como agentes facilitadores da aprendizagem, destaca-se a importância de as escolas brasileiras (rede pública e privada) se tornarem mais tecnológicas. Para tanto, reafirma-se a necessidade de formação docente de qualidade, com, base em um paradigma tecnológico, com sólida junção de teoria e prática, híbrida, que contemplem momentos presenciais com os virtuais, com condições de colocar os conhecimentos adquiridos durante o curso, na prática cotidiana das escolas. Para tanto, requer o acesso a recursos tecnológicos digitais e conectividade tanto para professores, quanto para alunos nos âmbitos das instituições escolares em nível nacional.

O maior desafio enfrentado pelos professores foi o de ter de utilizar-se dos meios tecnológicos sem estar completamente preparados, levando-os a uma reorganização coletiva em meio à crise pandêmica instalada. Esta atitude, de ordem coletiva, evidenciou mais ainda o que há tempos no meio educacional já se defendia: a tecnologia digital é necessária e importante para os processos de ensino e aprendizagem; a tecnologia só tem sentido com a mediação do/a professor/a. 
Houve esforço considerável por parte das famílias e nunca ficou tão evidente o seu papel preponderante e determinante para a promoção da aprendizagem. E neste aspecto, as TDICs tem potencial sim, mas com mediação intencionalmente planejada. Ou seja, o quão é importante nos processos de aprendizagem a mediação do/a professor/a, pois tecnologia é apenas meio. E isto ficou bem claro, pois sem a intervenção do/a professor/a para o estudante avançar, o processo de aprendizagem fica estagnado, comprometido e paralisado. E este foi um dos maiores aprendizados suscitados neste tempo pandêmico: a importância do papel do/a professor/a como mediador/a para a ocorrência da aprendizagem, sobretudo, em parceria com as famílias.

As tecnologias sempre fizeram e farão parte do desenvolvimento da humanidade. Durante o período da pandemia, apresentaram-se como possibilidades potenciais para professores e estudantes terem acesso às informações, a comunicação interativa uns com os outros, em seus mais diferentes níveis de realidade, para além da presencialidade física, apesar de uma grande parte considerável da sociedade encontrar-se ainda excluída desse processo.

Enfim, em tempos de tantas incertezas e diante de um novo cenário jamais imaginado, de crise sanitarista provocado pela COVID 19, o ano escolar de 2020 no Brasil foi nutrido por um lado de desafios e dificuldades, mas por outro lado, é válido sinalizar que foi perpassado também por oportunidades de novas aprendizagens, entre elas: maior interação e colaboração entre todos do contexto educacional, anunciando um novo cenário comunicativo; reflexões sobre o uso significativo das tecnologias digitais nos processos de ensino e aprendizagem após a pandemia; importância de se investir na formação de professores acerca das tecnologias digitais, bem como de se analisar melhor as condições das escolas quanto à disponibilidade destes recursos para sua utilização sempre que necessário e com maior frequência, tendo em vista a possibilidade de potencializar cada vez mais os processos de ensino e de aprendizagem. Para que desse modo o ensino a distância e o presencial se complementem a partir de elementos virtuais e reais, aumentando-se consideravelmente a eficácia na qualidade da aprendizagem que aponta para o Ensino Híbrido.

Lembrando sempre que o potencial das tecnologias se reveste de um saber fazer pedagógico, por isso a importância dos profissionais da educação na escolha dos melhores caminhos que possibilitem aprendizagens significativas.

\section{Referências}

Alencar, E.M. L.S. Bruno-Faria, M. de F. \& Fleith, D. S. (2010). Medidas de criatividade. Porto Alegre: Artmed.

Almeida, N. A. (Coord.).(2014). Os diferentes aspectos da linguagem na comunicação. In N.A. Almeida (Coord.). Tecnologias na escola: abordagem pedagógica e abordagem técnica. São Paulo: Cengage Learning.

Araújo, L. S. A. (2017). Repercussões da formação para o uso de tecnologias na subjetividade de professores, numa perspectiva de complexidade e autoria. 354f. Tese (Doutorado) Universidade Católica de Brasília, Distrito Federal.

Alves, L. Santos, B. \& Gonçalves, L. (2017). Impacto das ações formativas no uso de tecnologias nas práticas docentes. Revista Psicologia: Teoria e prática 19(3), 316-334. 
Bardin, L. (2002). Análise de Conteúdo. Edições 70, São Paulo: Livraria Martins Fontes.

Belloni, M. L. (2005). O que é Mídia educação. 2 ed, Campinas: Autores associados.

Castells, M. (2001). A Galáxia Internet: reflexões sobre internet, negócios e sociedade. Lisboa: Fundação Calouste Gulbenkian.

Champaoski, E. B. e Mendes, A. A. P. (2017). Percepção de professores do Ensino Fundamental acerca das tecnologias digitais no cotidiano escolar. Em Almeida, S. C, , Luciano, F. M., Mattar, João. (Or). Educação e tecnologias: refletindo e transformando o cotidiano. (5271). São Paulo: Artesanato Educacional.

Coll, C. \& Monereo, C. (2010). Educação e aprendizagem no século XXI. Porto Alegre: Artmed. In C. Coll, C, Monereo, Psicologia da educação virtual:aprender e ensinar com as tecnologias da informação e da comunicação. Porto Alegre: Artmed.

Brasil (2020). Coordenação do Conselho Pleno. Nota explicativa no 4 / 2020 cocp - cee- 18461 reanp - educação infantil. Goiânia, 2020. Recuperado de https://bit.ly/3yPPDnY.

Decreto Legislativo N. ${ }^{\circ} 6$ de 2020. Reconhece, para os fins do art. 65 da Lei Complementar $n^{\circ} 101$, de 4 de maio de 2000, a ocorrência do estado de calamidade pública, nos termos da solicitação do Presidente da República encaminhada por meio da Mensagem $n^{0}$ 93, de 18 de março de 2020. Recuperado de https://bit.ly/3i1H83n

Decreto No 9.057, de 25 de maio de 2017. Regulamenta o art. 80 da Lei 9.394/96, de 20 de dezembro de 1996, que estabelece as diretrizes e bases da educação nacional. Recuperado de https://bit.ly/3wJo4uF.

Demo, P. (2009). Educação Hoje: "novas" tecnologias, pressões e oportunidades. São Paulo: Atlas.

Freire,W. (org.); Dimmi A. et al. (2011). Tecnologia e educação: as mídias na prática docente.2. ed. Rio de Janeiro: Wak Ed.

Lei $N^{0}$ 14.040, de 18 de agosto de 2020. Estabelece normas educacionais excepcionais a serem adotadas durante o estado de calamidade pública reconhecido pelo Decreto Legislativo $\mathrm{n}^{0}$ 6, de 20 de março de 2020; e altera a Lei n 11.947, de 16 de junho de 2009. Recuperado de https://bit.ly/3c39u9K.

Lévy, P. (2010). Cibercultura.3.ed. São Paulo: Ed.34.

Litto, F. M. (2010). Aprendizagem a distância. (arquivos). São Paulo: Imprensa oficial do estado de São Paulo. Recuperado de https://bit.ly/3c8fKgp

Moran, J. M. (2015). Educação Híbrida: um conceito-chave para a educação, hoje. Em Bacich, L, Neto, Adolfo, T., Trevisani, F. M. Ensino híbrido: personalização e tecnologia na educação. (27-45). Porto Alegre: Penso.

Moran, J.M. (2001). Novos desafios na educação: a internet na educação presencial e virtual. (site). Porto, editora daUFPel, Pelotas. Recuperado de https://bit.ly/3vx2rO9

Morin, E. (2007). O método 6: ética. 3. ed. Porto Alegre: Sulina.

Morin, E. (2010). Os sete saberes necessários à educação do futuro. 8. ed. São Paulo: Cortez; Brasilia, DF: UNESCO.

Murray, J. H. (2003). Hamlet no holodeck: o futuro da narrativa no ciberespaço. São Paulo: Itaú Cultural:Unesp.

Nicolescu, B. (1999). O manifesto da transdisciplinaridade. São Paulo: TRIOM.

Palfrey, J. \& Gasser U. (2011). Nascidos na era digital: entendendo a primeira geração dos nativos digitais. Porto Alegre: Artmed.

Parecer CNE/CP nº 9/2020. Parecer homologado parcialmente Cf. Despacho do Ministro, publicado no D.O.U. de 1\%/6/2020, Seção 1, Pág. 32. Ver Parecer CNE/CP nº 9/2020 Recuperado de https://bit.ly/340W5nU.

Pretto, N. L. (2008). Escritos sobre educação, comunicação e cultura. Campinas, SP: Papirus.

Ribeiro, L. (2020). Aprenda desaprenda Reaprenda. Recife: Pipa Comunicação. 